\title{
A Sociologia Crítica de Josué Pereira da Silva
}

\author{
Caio César Pedron ${ }^{1}$
}

\begin{abstract}
SILVA, Josué Pereira da. Sociologia Crítica e Crise da Esquerda. São Paulo: Intermeios, 2019.
\end{abstract}

O esforço teórico presente em "Sociologia Crítica e Crise da Esquerda" contempla a produção intelectual de Josué Pereira da Silva do último decênio. Em suas próprias palavras ${ }^{2}$, tratava-se de fechar um ciclo virtuoso que contemplou os anos de docência (SILVA, 2019, p. 17) como professor de sociologia do Instituto de Filosofia e Ciências Humanas da UNICAMP. Fechamento de ciclo implica esforço de síntese e tentativa de conciliação das partes díspares de um coração teórico rebelde e é exatamente isso que Josué pretende consolidar através de uma teoria da justiça social que contemple uma pluralidade de vozes (Honneth, Fraser, Caillé, Souza Santos e André Gorz) sem perder de vista o horizonte da emancipação objetivo, isto é, sem deixar de procurar em projetos concretos a possibilidade de emancipação do homem, nisso reside seu interesse no debate sobre a Renda Básica de Cidadania, Alocação Universal, Renda de Base (SILVA, 2019, p. 184), e tantos outros nomes que foram dados à transferência de renda.

\footnotetext{
1 Mestre em Sociologia pelo programa de pós-graduação em sociologia do Instituto de Filosofia e Ciências Humanas da Universidade Estadual de Campinas (IFCH/UNICAMP). E-mail: caiopedron99@gmail.com

2 Suas próprias palavras durante o lançamento do livro e nos debates que tivemos, sobretudo, no texto que serve de epílogo a esta obra, o seu diagnóstico crítico de época, "What is Left".
} 
É sob esse prisma teórico conceitual e prático político que se desenrola toda a argumentação deste livro. Nos cinco primeiros capítulos Josué constrói o seu aporte analítico - sua sociologia crítica - e, nos quatro últimos, caminha em direção a uma resposta concreta, a renda básica incondicional; finalizando o seu empreendimento com um diagnóstico crítico de época: uma resposta crítica a crise da esquerda.

Começamos por uma aula inaugural (2016), misturam-se Habermas, Bordieu, Giddens, aos temas de tempo de trabalho, reconhecimento e redistribuição, combinam-se diferentes matizes que formam as preocupações do autor que viriam a se tornar maiores com o passar do tempo e, também, dos capítulos, é uma explicação do próprio autor sobre o seu desenvolvimento enquanto pesquisador e professor da Unicamp. No segundo capítulo, Silva nos introduz ao problema central deste livro: o que se pretende chamar de crítico na sociologia crítica? Aqui o autor apresenta os protagonistas do seu debate - Honneth, Fraser, Boaventura, Caillé (e, de maneira mais externa, André Gorz).

No capítulo seguinte a teoria da "escassez" ou imaterialidade do tempo de trabalho de André Gorz nos é apresentada com uma forte ênfase no aspecto de desenvolvimento de sua crítica ao marxismo ortodoxo, isso porque Gorz inicia o seu debate tratando de redução do tempo de trabalho e da apropriação coletiva dos aparelhos produtivos e termina defendendo modelos de renda básica incondicional. Neste ínterim, sua reflexão acentua a discrepância entre a realidade da microeletrônica, da crise ecológica global, do desemprego estrutural e do fim do trabalho em referência aos velhos modelos de crescimento econômico e pleno emprego, com as palavras de Josué:

Suas proposições consistiam em duas propostas articuladas. Uma política de redução programada do tempo de trabalho, condição primeira para uma política de criação de empregos numa época caracterizada pela diminuição da quantidade de trabalho socialmente necessário disponível no conjunto da sociedade. 


\begin{abstract}
A redução do tempo de trabalho permitiria uma redistribuição do trabalho existente entre as pessoas que querem trabalhar. Mas a política de redução do tempo de trabalho, por ele concebida, só seria possível se articulada com a implementação de uma renda de cidadania, financiada por impostos e desvinculada da quantidade de trabalho que a pessoa forneceria à sociedade. Essa última proposta complementaria a primeira e tornaria possível uma redução do tempo de trabalho sem redução de renda, deslocando o problema do financiamento da redução do tempo de trabalho da dimensão microeconômica (empresa) para a dimensão macroeconômica (conjunto da economia) (SILVA, 2019, p. 68-69).
\end{abstract}

No capítulo quatro o objetivo é desvendar as relações entre trabalho e reconhecimento em Axel Honneth - este texto conecta as preocupações do trabalho próprias de André Gorz aos próximos capítulos, cujo enfoque está dado sob a ideia de reconhecimento em seu choque/consonância para com a redistribuição - aqui, como parece costumeiro na obra de Josué, procura-se encontrar os fios de continuidade e ruptura ao largo do desenvolvimento da obra. A engenhosa síntese de Marx se expressa na fusão da teoria da emancipação e análise da sociedade "por meio de uma filosofia especulativa da história, cujo fundamento era o conceito de trabalho social" (SILVA, 2019, p. 86), permitia-o conectar os conceitos econômicos da "Crítica da economia política" a um espectro normativo e substantivo do trabalho social, criativo e promotor da própria humanidade.

É deste caldo reflexivo - conectando os escritos do jovem Hegel a George Hebert Mead - que nasce a famosa tríade: amor, direito e solidariedade. Amor deixado para a experiência familiar, amorosa e amigável; o direito à emergência do Estado e a luta dos grupos por reconhecimento nele e a solidariedade estaria posta no campo econômico. Aliás, Josué Pereira da Silva percebe que há uma guinada na teoria intersubjetivista de Honneth, pois, no prosseguimento de sua obra, ela deixa de conter a solidariedade e 
passa a ter o princípio do mérito ${ }^{3}$ como norteador da experiências no "sistema" econômico.

Essa preocupação de Josué, em relacionar o tema do trabalho ao debate sobre reconhecimento, aparece de forma mais matizada no capítulo seguinte ao de Honneth. Desta vez o que interessa é valorizar a teoria do reconhecimento de Boaventura de Souza Santos, esta reflexão leva muito mais em conta a experiência dos povos americanos e está definitivamente mais "localizada" que as eurocêntricas teorias do reconhecimento produzidas até então. Boaventura, como Honneth, começa a sua reconstrução da teoria da redistribuição e reconhecimento por Hegel, mas é a crítica feroz aos pressupostos eurocêntricos do autor que orienta o português - ao contrário do alemão - e coloca, em contraposição, a ideia de "Nuestra América" de José Martí como fundamento de sua proposta.

A sua teoria da emancipação requer uma justiça cognitiva global, substituição da crítica indolenteocidental pela epistemologia do sul, que está ancorada em três processos convergentes: sociologia da ausências, sociologia das emergências e trabalho de tradução. O primeiro trata de demonstrar que o não existente é produzido ativamente e que o objetivo central da sociologia das ausências é tornar possíveis e creditáveis essas impossibilidades socialmente produzidas, expandindo o presente (SILVA, 2019, p. 117) e as possibilidades "perdidas" pelos processos de racionalização ocidentais. A sociologia das emergências está dada no processo de substituir o futuro da razão indolente, com sua temporalidade linear e vazia, por um futuro "contraído" no presente, identificando as possibilidades e os sinais futuros no tempo de agora. $\mathrm{O}$ trabalho de tradução, por fim, visa o exercício de construir uma teoria geral

\footnotetext{
${ }^{3}$ Agradeço a leitura atenta de Isabela da Silva Coltro, a pesquisadora apontou aqui que a "virada" de Honneth pode ser compreendida como mudança normativa diante de um diagnóstico de um tempo que havia se alterado substancialmente. Deste ponto de vista, o pensamento de Honneth não foi colonizado pelo "sistema", mas identificou que a solidariedade possível no sistema capitalista havia se tornado pura meritocracia.
} 
sobre a impossibilidade da teoria geral, um exercício reflexivo que leve em conta a tradução das diferentes fontes de conhecimento, não só as científicas, mas, também, os conhecimentos tradicionais e as experiências dos povos oprimidos.

A sua teoria do reconhecimento e desigualdade está amparada ao paradigma das epistemologias do sul, são elas que precisam apresentar formas de responder à desigualdade e à exclusão que são, nas Américas, parte constitutiva da ordem e não resíduos ou exceções, como no continente europeu. Por isso, unese Marx (desigualdade) e Focault (exclusão) para compreender melhor os debates sobre colonialismo e racismo. As formas de combinação de um sistema de desigualdade e de exclusão são as mais tópicas, sendo, os modelos apresentados por Santos, apenas tipos ideais que se comungam na experiência para produzir as formas de degradação humanas às mais diversas. Portanto, seria possível combinar um regime de exclusão com certo regime de desigualdade; pode-se, por exemplo, unir um modelo de exclusão racista a um modelo de desigualdade de mercado, ou, elevando as tensões, levar o modelo de exclusão ao extermínio e o de desigualdade a miséria.

São necessários novos manifestos - não únicos como o de Marx - mais plurais, sobre os temas: democracia participativa; sistemas de produção alternativos; multiculturalismos; justiças e cidadanias emancipatórias; biodiversidade; conhecimentos rivais e direitos de propriedade intelectual; novo internacionalismo operário. Podemos repensar, sobre esse prisma, a experiência do fórum social mundial, que tratou, em certa medida, de todos os temas propostos por Santos, essa experiência nas américas, fartamente documentada pelo próprio Boaventura de Souza Santos, orientou o autor para pensar em três grandes princípios guias de teorização e ação política: democratizar, desmercantilizar e descolonizar.

Boaventura de Souza Santos serve, aos propósitos do livro, como um conector entre a razão ocidental - crítica, mas um pouco indolente - aos esforços para debater reconhecimento e redistribuição no pensamento brasileiro. Essa estratégia conceitual 
tem o fim de valorizar a especificidade do debate brasileiro em contraposição aos limites teóricos da produção eurocêntrica. No capítulo 6, Silva nos introduz ao cenário do debate por direitos civis, políticos e sociais no contexto brasileiro, este que tem muitas especificidades, pois aqui os debates da década de 80 eram os da redemocratização, da reconquista de direitos políticos e civis básicos e não na consolidação dos direitos sociais como era na Europa.

O debate da redistribuição e do reconhecimento surge tardiamente, nos anos 2000, através da consolidação da luta dos movimentos sociais por direito à diferença e, no campo da redistribuição, no debate sobre os programas de transferência de renda - o choque entre transferência condicional e incondicional. Esse tema da redistribuição conecta o capítulo seis aos dois capítulos seguintes, pois no capítulo sete o que interessa é salientar o choque entre a transferência condicional e incondicional e, no capítulo 8, discutir o problema da renda básica à luz dos desdobramentos que levaram ao impeachment Dilma Rousseff e a posterior eleição de Jair Messias Bolsonaro, inimigo público dos programas que, até então, eram carros mestres da política pública estatal.

No capítulo sobre o problema da (in) condicionalidade e sua relação para com a justiça, Silva enfatiza a emergência dos programas de renda condicional e incondicional no governo de Luiz Inácio Lula da Silva, o programa de renda condicionado aquele que exige certas condições que devem ser cumpridas para que ocorra a transferência de renda - tornou-se o principal instrumento de política redistributiva do governo com o PBF (Programa Bolsa Família) enquanto o projeto de renda básica do Senador Suplicy, foi outorgado por Lula, mas nunca ganhou a forma de uma política pública.

Josué Pereira da Silva defende a incondicionalidade, pois crê que há nela um conteúdo de desmercantilização das relações sociais - uma possibilidade real de reforma revolucionária -, pois a universalização de tal política implicaria no debacle da crença em uma sociedade de "pleno emprego" ou na própria categoria de trabalho social como única forma de emancipação e reconhecimento 
intersubjetivo do homem. Este conteúdo normativo está ausente das políticas sociais propostas com o viés da condicionalidade, isso porque elas são provisórias - tem-se a intenção de reinserir os seus participantes, ou ao menos de preparar a geração familiar seguinte para o mercado de trabalho - e oferecidas apenas aos necessitados, ainda com um conjunto de obrigações que produzem um resultado muito errático, ou, no mínimo, questionável do ponto de vista do reconhecimento desses sujeitos que o recebem.

Ironicamente, o capítulo oito - tempos difíceis para a renda básica - aponta a centralidade do tema da renda básica em tempos de crise econômica e empobrecimento geral da população, esta que havia sido relegada à segundo plano no governo Bolsonaro. Contudo, paradoxalmente, a pandemia fez com que o debate sobre a renda básica voltasse com maior força, sendo encampado em todo mundo como uma resposta plausível e necessária à crise social que seria fruto dos efeitos perversos do combate ao vírus. Bolsonaro e seu ministro da economia deixaram de lado o credo neoliberal e precisaram adotar medidas de proteção social frente à crise econômica, promovendo o auxílio emergencial e o seguro desemprego como respostas ao desamparo maciço que se avizinhava. Parece que a tábua de salvação do governo Bolsonaro está assentada na forma como será constituída a política de proteção social e investimento no pós-crise e, por isso, o trabalho de Josué Pereira da Silva (2019) constitui-se como leitura indispensável para a formação do pensamento social pós-pandemia.

Como no ditado popular que afirma que o bom vinho é aquele que resiste bem ao tempo, amadurece e fornece uma tonalidade de sabores mais intensos conforme o passar dos anos, este livro de Josué Pereira da Silva tem a virtude de se mostrar melhor conforme o tempo passa. Além de nos apresentar e mostrar as minúcias de um debate teórico e prático que está na ordem do dia, o livro faz com que pensemos em soluções para a crise atual à luz de referências dadas antes de sua ocorrência. Josué não é nenhum mago ou profeta, mas o seu texto sobre a esquerda e o que sobra dela, permanece tão conectado ao presente quanto o debate sobre a renda básica, demonstrando o aguçado senso crítico da 
realidade que faz transbordar de sentido uma reflexão feita antes da grande pandemia que "inaugura" o nosso século.

A hegemonia petista soçobrou diante da emergência dos novos atores da direita global e do esfacelamento de sua política social-liberal de distribuição possível da renda dentro dos quadros da ordem instituída no Brasil. Para Silva, o modelo petista de conciliação e reformismo fraco não poderia ser retomado e a esquerda deveria repensar todo o paradigma no qual estava assentada a sua política durante os governos PT. Sem uma resposta radical, que combinasse política redistributivas e de reconhecimento, sob a base de uma nova forma de sociabilidade e de produção de conhecimento descolonizado, não seria possível contrapor-se a força do capitalismo em sua forma mais radical.

Na concepção de Silva, a esquerda precisa repensar se deve ou não manter a estratégia petista de alcançar o poder estatal, mesmo que tendo de negociar com as elites econômicas após a sua vitória. A esquerda precisa incentivar os processos de democratização de "alta intensidade", participativa e representativa, e precisa lutar por políticas que se pretendam - como a renda básica uma universalização combinada à superação do paradigma do trabalho, este que hoje limita tanto a esquerda ortodoxa quanto a direita. Precisamos desmercantilizar as relações humanas (re) incrustando-as na sociedade, descolonizar o pensamento social e prepara-lo para responder as demandas nacionais para, enfim, verdadeiramente, democratizar a esfera pública, fortalecendo a representatividade de grupos subalternos e permitindo uma vida mais justa para toda a humanidade.

\section{Referências}

SILVA, Josué Pereira da. Sociologia Crítica e Crise da Esquerda. São Paulo: Intermeios, 2019. 